\title{
Comparison of ferric carboxymaltose versus Iron Sucrose for treatment of iron deficiency anemia in pregnancy.
}

\footnotetext{
1. MBBS

Post Graduate Resident Obstetrics and Gynecology Madina Teaching Hospital Faisalabad.

2. MBBS, FCPS

Associate Professor Obstetrics and Gynecology University Medical and Dental College Faisalabad.

3. MBBS, MCPS, FCPS

Professor Obstetrics and Gynecology University Medical and Dental College Faisalabad.

4. MBBS, MCPS, FCPS

Assistant Professor Obstetrics and Gynecology University Medical and Dental College Faisalabad.

5. MBBS, FCPS

Assistant Professor Obstetrics and Gynecology University Medical and Dental College Faisalabad.
}

Correspondence Address:

Dr. Humaira Zafar

Department of Obstetrics and

Gynecology

University Medical and Dental College

Faisalabad.

humairazafar75@gmail.com

Article received on:

08/08/2020

Accepted for publication:

$24 / 10 / 2020$
Hira Jamal', Humaira Zafar ${ }^{2}$, Mubashra $\mathrm{Naz}^{3}$, Umber Fatima ${ }^{4}$, Anees Fatima ${ }^{5}$

ABSTRACT... Objective: To compare the mean increase in hemoglobin level with ferric carboxymaltose injection and iron sucrose injection for the management of the pregnant females presenting with iron deficiency anemia. Study Design: Randomized Controlled Trial. Settings: Department of Obstetrics and Gynecology Madina Teaching Hospital affiliated with University medical and Dental College Faisalabad. Period: July 2019 to December 2019. Material \& Method: A total number of 100 patients presented in OPD satisfying the selection criteria were enrolled in the study. The patients were randomly divided in two groups. In group $A$, females were given ferric carboxymaltose and in group $B$, females were given iron sucrose. After calculating the total iron deficit, patients in group A were given intravenous FCM. Patients in group B were given IS. Follow up of the patient was done after 3 weeks of intravenous iron treatment. The baseline $\mathrm{Hb}$ and values after 3 weeks of intravenous iron treatment were compared between the FCM and IS groups and increase in $\mathrm{Hb}$ level calculated as mean and $\mathrm{SD}$. Both groups were analyzed for rise in $\mathrm{Hb}$ level by using independent sample $t$ test. $P$ value $<0.05$ was taken as significant. Results: $A$ total 100 pregnant female were found eligible for study, and were randomized into two groups of 50 each. Mean increase in hemoglobin level with ferric carboxymaltose and iron sucrose was evaluated, it shows that baseline $\mathrm{Hb}$ was $8.84 \pm 0.68$ in Group A and $8.78 \pm 0.76$ in Group B, P value was 0.67 , after treatment $\mathrm{Hb}$ was $12.02 \pm 0.89$ in Group A and $10.92 \pm 0.99$ in Group B. Mean increase was $3.18 \pm 0.60$ in Group A and $2.14 \pm 0.81$ in Group B. P value was 0.001 . Conclusion: Ferric carboxymaltose significantly increase $\mathrm{Hb}$ level and restores the iron stores as compare to iron sucreose. FCM is safe and effective intravenous treatment for iron deficiency anemia in pregnancy. FCM has the advantages of single large dose administration and fewer hospital visit. FCM is most suitable drug for the treatment of patients with IDA who required quick replenishment of iron stores.

Key words: $\quad$ Ferric Carboxymaltose, Iron sucrose, Iron Deficiency Anemia.

Article Citation: Jamal H, Zafar H, Naz M, Fatima U, Fatima A. Comparison of ferric carboxymaltose versus Iron Sucrose for treatment of iron deficiency anemia in pregnancy. Professional Med J 2021; 28(4):481-484. https://doi.org/10.29309/TPMJ/2021.28.04.5935

\section{INTRODUCTION}

Anemia during pregnancy is a major health issue all over the world. ${ }^{1}$ Iron deficiency anemia is the most common type of anemia and its prevalence is high in South Asia. ${ }^{2}$ The incidence of anemia in pregnancy is $42 \%{ }^{3}$ In Pregnancy the requirement of iron increased with average of $1000 \mathrm{mg} .{ }^{4}$ The reasons for anemia are low dietary intake of iron, repeated pregnancies, poor bio -availability of iron, chronic blood loss and infections like malaria, hookworm infestation. ${ }^{5}$

The clinical manifestations of anemia are shortness of breath, palpitations, easy fatigue ability, poor concentration. ${ }^{6}$ Iron deficiency is significantly associated with poor maternal and fetal outcome. There is increase risk of preterm labor, intrauterine growth restriction, low birth weight infants. ${ }^{7}$ Iron deficient mothers are at risk of delivering iron deficient neonates. ${ }^{8}$

Parentral iron treatment is safe, effective, well tolerated and rapidly restore the iron stores in pregnancy. ${ }^{9}$ The most commonly used parentral preparations are IS and iron dextran, their side effects include nausea, dizziness and local irritation. ${ }^{10} \mathrm{~A}$ novel iron formulation ferric carboxymaltose is considered to be a better 
potential for replenishing iron stores in short time, minimum side effects and better tolerance. ${ }^{11}$

\section{MATERIAL \& METHODS}

The study was conducted in the department of Obstetrics and Gynecology Madina Teaching Hospital affiliated with University Medical and Dental College Faisalabad between July 2019 to December 2019.

\section{Inclusion Criteria}

All patients diagnosed with IDA of age 18-40 years, between 24-36 weeks of gestation.

\section{Exclusion Criteria}

Patients with anemia other than iron deficiency like sickle cell anemia and thalasaemia.

A total number of 100 patients presented in OPD satisfying the selection criteria were enrolled in the study after permission from ethical committee. Informed consent was obtained and patient's demographic information (name, age, gestational age and parity) was recorded.

On enrollment, a detailed clinical history which includes previous iron treatment and chronic medical illness was taken. Clinical examination was done. Routine antenatal investigations were performed according to unit protocol. Investigations for anemia include hemoglobin, reticulocyte count, peripheral film and red cell indices, serum ferritin level and $\mathrm{Hb}$ electrophoresis if indicated. The patients were randomly divided in two groups. In group $A$, females were given ferric carboxymaltose and in group $B$, females were given iron sucrose.

Iron requirement assessed according to Ganzoni's formula.

After calculating the total iron requirement, patients in group A were administered intravenous FCM. Maximum dose per sitting was 1000mg which was diluted in $200 \mathrm{ml} 0.9 \%$ normal saline and given as an IV infusion over 30 minutes. Successive doses (if required) were infused on day 7 and day 14 .
Patients in group B were given IS maximum dose of $200 \mathrm{mg}$ diluted in $200 \mathrm{ml}$ normal saline as slow infusion over 30 minutes on alternate day, maximum 600mg /week.

A test dose was given to check for any adverse reaction for both, FCM and IS.

Follow up of the patient was done after 3 weeks of intravenous iron treatment. The baseline $\mathrm{Hb}$ and values after 3 weeks of intravenous iron treatment were compared between the FCM and IS groups and increase in $\mathrm{Hb}$ level calculated as mean and $\mathrm{SD}$. Both groups were analyzed for rise in $\mathrm{Hb}$ level by using independent sample t test. $P$ value $<0.05$ was taken as significant.

\section{RESULTS}

A total 100 pregnant female were qualified for study, and were randomized into two groups of 50 each. All 100 patients completed the treatment and were included in analysis.

Age distribution shows that $64 \%(n=32)$ in Group A and $66 \%(n=33)$ in Group B were between 1830 years of age whereas $36 \%(n=18)$ in Group A and $34 \%(n=17)$ in Group B were between $31-40$ years of age, mean age was $29.38 \pm 3.69$ years in Group A and $29.14 \pm 3.77$ years in Group B. (Table-I)

Regarding gestational age $665 \%(n=66)$ patients in Group A and $62 \%(n=31)$ in Group B were between 25-34 weeks of gestation whereas 34\% $(n=17)$ in Group A and 38\% $(n=19)$ in Group $B$ were between 34-36 weeks of gestation. Mean age was $32.1 \pm 3.53$ weeks in Group $A$ and $32.28 \pm 3.57$ weeks in Group B. (Table-II)

Mean increase in hemoglobin level with ferric carboxymaltose and iron sucrose was evaluated, it shows that baseline $\mathrm{Hb}$ was $8.84 \pm 0.68$ in Group $A$ and $8.78 \pm 0.76$ in Group B, P value was 0.67, after treatment $\mathrm{Hb}$ was $12.02 \pm 0.89$ in Group $A$ and $10.92 \pm 0.99$ in Group B.

Mean increase was $3.18 \pm 0.60$ in Group $A$ and $2.14 \pm 0.81$ in Group B. P value was 0.001 . (TableIII) 


\begin{tabular}{|c|c|c|c|c|c|c|}
\hline \multirow{2}{*}{$\begin{array}{l}\text { Age (in } \\
\text { year) }\end{array}$} & \multicolumn{3}{|c|}{ Group-A $(n=50)$} & \multicolumn{3}{|c|}{ Group-A $(n=50)$} \\
\hline & \multicolumn{2}{|c|}{$\begin{array}{c}\text { No. of } \\
\text { Patients }\end{array}$} & $\%$ & \multicolumn{2}{|c|}{$\begin{array}{c}\text { No. of } \\
\text { Patients }\end{array}$} & $\%$ \\
\hline $18-30$ & \multicolumn{2}{|r|}{32} & 64 & \multicolumn{2}{|c|}{33} & 66 \\
\hline $31-40$ & \multicolumn{2}{|r|}{18} & 36 & \multicolumn{2}{|c|}{17} & 34 \\
\hline Total & \multicolumn{2}{|r|}{50} & 100 & \multicolumn{2}{|c|}{50} & 100 \\
\hline Mean $\pm S D$ & \multicolumn{3}{|c|}{$29.38 \pm 3.69$} & \multicolumn{3}{|c|}{$29.14 \pm 3.77$} \\
\hline \multicolumn{7}{|c|}{ Table-I. Age distribution $(n=100)$} \\
\hline \multirow{2}{*}{$\begin{array}{c}\text { G.Age (in } \\
\text { weeks) }\end{array}$} & \multicolumn{3}{|c|}{ Group-A $(n=50)$} & \multicolumn{3}{|c|}{ Group-B $(n=50)$} \\
\hline & \multicolumn{2}{|c|}{$\begin{array}{l}\text { No. of } \\
\text { Patients }\end{array}$} & $\%$ & \multicolumn{2}{|c|}{$\begin{array}{l}\text { No. of } \\
\text { Patients }\end{array}$} & $\%$ \\
\hline $25-34$ & \multicolumn{2}{|r|}{33} & 66 & \multicolumn{2}{|c|}{31} & 62 \\
\hline$>34$ & \multicolumn{2}{|r|}{17} & 34 & \multicolumn{2}{|c|}{19} & 38 \\
\hline Total & \multicolumn{2}{|r|}{50} & 100 & \multicolumn{2}{|c|}{50} & 100 \\
\hline Mean $\pm S D$ & \multicolumn{3}{|c|}{$32.1 \pm 3.53$} & \multicolumn{3}{|c|}{$32.28 \pm 3.57$} \\
\hline \multicolumn{7}{|c|}{ Table-II. Gestational age $(n=100)$} \\
\hline $\mathrm{Hb}(\mathrm{g} / \mathrm{dl})$ & & $\begin{array}{l}\text { Grol } \\
\text { (n= }\end{array}$ & & $\begin{array}{l}\text { Grou } \\
\text { (n= }\end{array}$ & $\begin{array}{l}0-B \\
0)\end{array}$ & $\begin{array}{c}\text { P- } \\
\text { Value }\end{array}$ \\
\hline & & Mean & SD & Mean & SD & \\
\hline At baseline & & 8.84 & 0.68 & 8.78 & 0.76 & 0.67 \\
\hline After Treatm & ent & 12.02 & 0.89 & 10.92 & 0.99 & 0.0001 \\
\hline Mean Increa & & 3.18 & 0.60 & 2.14 & 0.81 & 0.001 \\
\hline $\begin{array}{l}\text { Table-III. } \\
\text { ferric car } \\
\text { injection fo }\end{array}$ & $\mathrm{me}$ & $\begin{array}{l}\text { In incre } \\
\text { ymaltos } \\
\text { anagem } \\
\text { deficien }\end{array}$ & $\begin{array}{l}\text { se in } h \\
\text { inject } \\
\text { nt of } f e \\
y \text { aner }\end{array}$ & $\begin{array}{l}\text { moglo } \\
\text { n and } \\
\text { nales }\end{array}$ & $\begin{array}{l}\text { oin lev } \\
\text { iron sı } \\
\text { resen } \\
100 \text { ) }\end{array}$ & $\begin{array}{l}\text { with } \\
\text { rose } \\
\text { ng with }\end{array}$ \\
\hline
\end{tabular}

\section{DISCUSSION}

Anemia in pregnancy is a global health concern. ${ }^{12}$ Anemia during pregnancy increase the risk of low birth weight, preterm labor, maternal and perinatal mortality with poor Apgar score. ${ }^{3}$ Anemia increase the risk of infection and maternal morbidity. ${ }^{13}$

The aim of the study was to compare the efficacy FCM with IS in female with iron deficiency anemia. This present study have its results consistent with a study conducted by Agarwal D in India. ${ }^{1}$

Cristoph et al conducted a study and found FCM more efficacious and safe than iron sucrose. ${ }^{5}$ Breymann $\mathrm{C}$ et al. concluded to consider FCM to be first line treatment option for correction of iron deficiency anemia. ${ }^{14}$

Froessler et al. have documented remarkably increased ferritin level after FCM infusion in females with iron deficiency anemia. ${ }^{15}$ A Khalafallah et al. demonstrate that FCM is more effective and convenient than other treatments. ${ }^{16}$ Qassim et al. concluded that no IV iron preparation appeared to be superior. ${ }^{17}$

A study conducted in UAE also demonstrate that IV FCM effectively increase hemoglobin in pregnant female with iron deficiency anemia. ${ }^{18}$ Another study conducted in Turkey also document that intravenous carboxymaltose improve hemoglobin in short time. ${ }^{19}$

Ferric carboxymaltose seems to be superior to other parentral iron formulations due to its high efficacy, safety and compliance revolutionizing the management of iron deficiency anemia during pregnancy. $^{20}$

\section{CONCLUSION}

Ferric carboxymaltose significantly increase $\mathrm{Hb}$ level and restores the iron stores as compare to iron sucreose. FCM is safe and effective intravenous treatment for iron deficiency anemia in pregnancy. FCM has the advantages of single large dose administration and fewer hospital visit. FCM is most suitable drug for the treatment of patients with IDA who required quick replenishment of iron stores.

\section{Copyright $(24$ Oct, 2020.}

\section{REFERENCES}

1. Agrawal D, Masand DL. A study for efficacy and safety of ferric carboxymaltose versus iron sucrose in iron deficiency anemia among pregnant women in tertiary care hospital. Int J Rprod Contracept Obstet Gynecol. 2019 June; 8(6):2280-2285.

2. Naqash $A$ et al. Effectiveness and safety of ferric carboxymaltose compared to iron sucrose in women with iron deficiency anemia: Phase IV clinical trials. BMC Women's Health (2018) 18:6.

3. FOGSI General Clinical Practice Recommendations. Management of iron deficiency anemia in pregnancy. 2016.

4. Friedrisch JR, Cancado RD. Intravenous ferric carb oxymaltose for the treatment of iron deficiency anemia. Braz J Hem Hemother. 2015; 37(6):400-5. 
5. Christoph P, Schuller C. Studer H .Irion O, De Tejada BM, Surbek $D$. Intravenous iron treatment in pregnancy: Comparison of high dose ferric carboxymaltose vs. Iron sucrose. J Perinatal Med. 2012; 40(5):469-74.

6. Guidelines for prevention of maternal anemia. Available at; http://www.nrhmtn.gov.in/guideline/ RGPMA.pdf.( Accessed on December 2018).

7. Auerbach M. Commentary: Iron deficiency of pregnancy- a new approach involving intravenous iron. Reproductive Health 2018, 15(Suppl 1): 96.

8. Zhao $G$, $X u$ G ,Zhou $M$ et al. Prenatal iron supplementation reduces maternal anemia, iron deficiency and iron deficiency anemia in a randomized clinical trial in China, but iron deficiency remains widespread in mothers and neonates $\mathrm{J}$ Nutr. 2015; 145:1916-23.

9. Zeba D. Intravenous iron treatment in pregnancy: Ferric carboxymaltose for correction of iron deficiency anemia Faridpur. Med Coll J 2017; 12 (2); 54-7.

10. Singh S, Dhama V, Chaudhary R, Singh P. Comparing the safety and efficacy of intravenous iron sucrose and intravenous ferric carboxymaltose in treating postpartum anemia. Int J Reprod contracept Obstet Gynecol. 2016; 5:1451-6.

11. Joshi SD, Chikkagowdra S, Kumar VCM. Comparative study of efficacy and safety of intravenous carboxymaltose versus iron sucrose in treatment of postpartum iron deficiency anemia. Int $\mathrm{J}$ Reprod Contracept Obstet Gynecol. 2016;5.

12. World Health Organization. Micronutrient deficiencies: Prevention and control guidelines. Geneva: World Health Organization, 2015. Available/ WHO- WFP UNICEF statement.pdf (Accessed on December 2018).
13. Anand $T$, Rahi $M$, Sharma $P$, Ingle GK. Issues in prevention of iron deficiency anemia in India. Nutrition. 2014; 30(7-8):764-70.

14. Breymann C, Milman N, Mezzacasa A, Bernard R, Dueudanhausen J. Ferric carboxymaltose vs. oral iron in the treatment of pregnant women with iron deficiency anemia; an international. Open - label, randomized controlled trial (FER-ASAP). J Perinat Med. 2017; 45(4):443-453.

15. Frosseler B. Gajic T, Dekker G, Hodyl NA. Treatment of iron deficiency anemia with intravenous ferric carboxymaltose in pregnancy. Arch Obstet Gynacol 2018; 4782-9.

16. A Khalafallah, Hyypa A, Chuang A et al. A prospective Randomized Controlled Trial of a Single intravenous infusion of carboxymaltose vs. single intravenous iron polymaltose or daily ferrous sulphate in the treatment of iron deficiency anemia in pregnancy. Seminars in Hematology 2018; 55(4):223-234.

17. Qassim A, Mol BW, Grivell RM, Gerzeskowiak LE. Safety and efficacy of intravenous iron polymaltose, iron sucrose and ferric carboxymaltose in pregnancy: $A$ systematic review. Aust NZ J Obstet Gynaecol.2018; 58(1):22-39.

18. Wani S, Noushad M, Ashiq S. Retrospective study to assess the effectiveness, tolerability and safety of ferric carboxymaltose in the management of iron deficiency anemia in pregnancy. Anemia 2019(4):1-5.

19. Helvacioglu C, Ekin M. The effect of iron carboxymaltose treatment on quality of life in women with iron deficiency. J Surg Med. 2020; 4(4): 00-00.

20. Garg R, Nigam A. Agrawa IP, Agrawa IR. Iron carboxymaltose: A safe and effective molecule to combar anemia in pregnancy. Int $\mathrm{J}$ Cur Res Aca Rev. 2016; 4(2):124-30.

\begin{tabular}{|c|l|l|l|}
\hline \multicolumn{3}{|c}{ AUTHORSHIP AND CONTRIBUTION DECLARATION } \\
\hline Sr. \# & \multicolumn{1}{|c|}{ Author(s) Full Name } & \multicolumn{1}{|c|}{ Contribution to the paper } & Author(s) Signature \\
\hline 1 & Hira Jamal & $\begin{array}{l}\text { Research conception, Data } \\
\text { collection. } \\
\text { Author }\end{array}$ \\
\hline 2 & Humaira Zafar & Review and Proof reading. \\
\hline 4 & Mubashra Naz & Statistical modeling. \\
\hline 5 & Anees Fatima & Discussion.
\end{tabular}

